\title{
The prosody of other-repetition in British and North American English
}

\section{Couper-Kuhlen, Elizabeth}

2020-09

Couper-Kuhlen , E 2020 , ' The prosody of other-repetition in British and North American

English ', Language in Society , vol. 49 , no. 4 , 004740452000024 , pp. 521-552 . https://doi.org/10.1017/S0047404

http://hdl.handle.net/10138/324271

https://doi.org/10.1017/S004740452000024X

cc_by_nc_nd

acceptedVersion

Downloaded from Helda, University of Helsinki institutional repository.

This is an electronic reprint of the original article.

This reprint may differ from the original in pagination and typographic detail.

Please cite the original version. 
The prosody of other-repetition in British and North American English

Elizabeth Couper-Kuhlen

University of Helsinki

Postal address:

Bogotastrasse 4

14163 Berlin, Germany

Email address:

elizabeth.couper-kuhlen@helsinki.fi 


\section{Abstract}

This study explores the link between prosody and other-repetition in a moderately large collection from everyday English talk-in-interaction $(\mathrm{n}=200)$. British English and North American English cases were analysed separately in order to track possible varietal differences. Of initial interest was the question whether focal pitch accents might disambiguate among other-repetition actions. The results indicate that only two out of six possible other-repetition actions are associated with distinct focal pitch contours in the two varieties. For all other actions speakers use many of the same pitch contours non-distinctively. Overall, falling contours appear more frequently in British other-repetitions, while rising contours are more frequent in North American other-repetitions. In conclusion, it is argued that in addition to pitch contour, prosodic features such as pitch span, loudness, and timing are crucial in distinguishing other-repetition actions, as are non-prosodic factors such as epistemic access (often reflected in $o h$-prefacing) and visible behavior.

\section{Keywords}

repair initiation, surprise, challenge, registering, pitch accents, $o h$-preface, epistemics 


\section{INTRODUCTION}

The motivation for this study comes from a simple observation in everyday talk-in-interaction: the lexical repetition of something an interlocutor has just said can make different actions by the recipient relevant next. Responding actions can range from minimal acknowledgement or bland confirmation of what has been repeated, to offerings of alternative formulations, re-phrasings, and corrections of what was said originally, as well as to explanations, justifications, and other kinds of self-defense dealing with its implications. Since a lexical repetition provides little new substantive content to the talkafter all, the interlocutor has just produced the words him/herself - there must be some other explanation for how recipients of a repetition know what action is called for next. One possible account is that the prosody of the repetition furnishes important cues as to what a speaker is doing when repeating the words of another in subsequent position.

This study explores the link between prosody and other-repetition in a moderately large collection of such turns from everyday English talk-in-interaction $(n=200)$. Initially the focus was on the type of focal pitch accent used in the repetition turn, but the investigation was subsequently expanded to include other prosodic features such as pitch span, pitch register, loudness, speech rate, and timing viewed in relation to the prior turn. The results indicate that pitch contours only partially disambiguate different types of other-repetition: in fact, the two varieties of English examined (British and North American) use many of the same contours for most other-repetition actions, albeit with regionally distinct preferences. Other prosodic features such as timing and pitch span furnish more reliable cues. Ultimately, however, these must be complemented by various kinds of verbal, visible, and contextual information.

\section{BACKGROUND}


English is known as an 'intonation' language, meaning that tonal contrasts are relevant not at the level of the lexicon but of the utterance (Couper-Kuhlen 1986, Cruttenden 1986/1997). Syllables in English utterances have differing degrees of perceived prominence depending on whether they are accented, stressed, or unstressed. ${ }^{1}$ Accented syllables are perceived to be prominent due primarily to pitch, while stressed syllables are prominent due to combinations of length, loudness, and vowel quality.

Unstressed syllables lack prominence altogether. If there are several accented syllables in an utterance, the last one is typically considered the main or primary one and referred to as the nucleus.

It is customary in descriptions of English intonation to distinguish different types of pitch accent, yet taxonomies differ depending on whether the approach is based on contours or levels (see Grice and Bauman 2007 for a recent overview). Contours, as advocated, e.g., by the British School (Crystal 1969, Couper-Kuhlen 1986, Cruttenden 1986/1997), are typically dynamic pitch patterns beginning on the nucleus and extending to the end of the intonation unit. ${ }^{2}$ Included minimally are falls, rises, fall-rises, rise-falls, and level contours. ${ }^{3}$ A levels approach such as that advocated in Autosegmental-Metrical phonology (Pierrehumbert 1980, Pierrehumbert and Hirschberg 1990) views pitch configurations as a succession of pitch levels, or targets, with fundamental frequency being interpolated in between them. Such a model for English postulates, for instance, two simple pitch accents $\mathrm{H}^{*}$ and $\mathrm{L}^{*}$, which align high and low tones respectively to a stressed syllable, and four complex ones $\mathrm{H}^{*}+\mathrm{L}, \mathrm{H}+\mathrm{L}^{*}, \mathrm{~L}^{*}+\mathrm{H}, \mathrm{L}+\mathrm{H}^{*}$, as well as two phrase accents $\mathrm{H}$ and $\mathrm{L}$, which mark the end of intermediate phrases, and two boundary tones $\mathrm{H} \%$ and $\mathrm{L} \%$, which mark the end of intonation phrases (Pierrehumbert and Hirschberg 1990). In this model, no distinction is made between nuclear and non-nuclear accents: the choice of pitch accents is the same everywhere in the intonation phrase.

We adopt a hybrid approach to pitch accents here: our focus is initially on the nuclear syllable, referred to as the 'focal' syllable (see below), and its pitch configuration up to the final syllable of the unit. These configurations are described in terms of the British-School taxonomy (fall, rise, fall-rise, rise-fall, and level contours). At the same time, the mapping of component pitches to the syllables 
involved is made as explicit as possible, as practiced in the levels approach, with the pitch on the final syllable, a sort of 'boundary tone', being considered independently of the last pitch-accent type. ${ }^{4}$ This makes it in principle possible to convert the British-School patterns into autosegmental notation much along the lines of Cruttenden (1997:61f.).

Concerning the function of pitch accents, English intonation specialists agree that the location of the nuclear accent is crucial for establishing the focus domain, that portion of the utterance that is being foregrounded in information-structural terms (see Lambrecht 1994). Focus can be narrow, covering a single element of the utterance, or broad, extending over multiple elements or indeed the whole utterance. Focus is marked in both cases through primary accent. Since some utterances in English conversation have more than one primary accent, we will use the terms 'focal accent' and 'focal syllable' in what follows.

It has often been speculated that pitch-accent type contributes to speech-act distinctions, the classical case being that between questions and statements. Questions are conventionally thought to have rising intonation, while statements are thought to have falling intonation. Yet Couper-Kuhlen (2012) investigated final pitch in a collection of questions extracted from a British radio call-in program and found no reliable correspondences between final rising pitch and sentence type (see also Geluykens 1988). Both yes-no interrogatives and so-called 'declarative questions' occasionally had final falling intonation. Questions thus cannot be reliably distinguished from statements based on final intonation (see also Heritage 2012a). Yet Couper-Kuhlen's (2012) study concerned only final intonation or 'boundary tones' and does not exclude the possibility that there might be some correlation between question or question type and pitch-accent type. ${ }^{5}$ The present study explores the possibility that pitch accents may disambiguate among another set of social actions, namely those implemented by other-repetitions that make a response relevant next (see Rossi this issue a).

There is already some indication in the literature that pitch accents may be a relevant cue to the work that other-repetition does in English. Besides the classic pragmatics-intonation literature based 
mainly on intuition (see, e.g., Quirk et al. 1972: 408-411 and Cruttenden 1986/1997:84-5 on "echo utterances"), Benjamin and Walker (2013) present evidence from conversation that speakers who repeat what an interlocutor has said using a 'high rise-fall contour' will be heard as implying that what has been said is wrong and stands in need of correction. The authors find no difference between cases in which the high rise-fall pattern is followed by a final rise and those in which it is not $(2013: 122 \mathrm{n})$. This would seem to imply that it is the pitch-accent type and not the boundary tone that characterizes this kind of action in other-repetition.

\section{DATA AND ANALYTIC PROCEDURE}

The data for this study come from a wide variety of two-party and multi-party everyday conversations, carried out both on the telephone and in face-to-face constellations. All repetition speakers are native speakers of English, with approximately one half speaking a variety of (modified standard) British English and one half a variety of North American English (Canadian or US-American). British English and North American English cases were collected and analysed separately. The results thus allow insight into the amount of overlap between the two varieties, as well as reveal characteristic patterns associated with other-repetition in each variety. ${ }^{6}$

The procedure has been as follows. First, all instances of other-repetition making a response relevant next, along with the surrounding sequential context, were culled from the recordings. Included were both partial and full lexical repetitions, with deictic adjustments (me -> you, etc.) as well as deletions or additions of minor elements being allowed. Candidate understandings were excluded (see Rossi this issue a for more information). ${ }^{7}$ Next, the prosody of the repetition turn was notated auditorily. Included were location of the main and secondary accents, type of main pitch accent together with any pitch movement at the end of the turn, as well as noticeable changes in pitch register, pitch span, loudness, speech rate, and transition timing in relation to the prior turn. Where 
necessary, acoustic analyses were carried out with the computer program Praat in order to back up impressionistic judgments and determine the exact temporal mapping of pitch and loudness events to syllables. Finally, a number of multi-modal details accompanying the repetition turn, including gaze direction, head movement, facial expression, and body position, were noted.

The examples were separated into British and North American sub-collections and were then examined sequentially in order to determine what action the other-repetition was analyzably accomplishing. The actions postulated were those that have emerged as relevant in the literature on other-repetition in English (e.g., Robinson 2013, Benjamin and Walker 2013, Walker and Benjamin 2017) and have otherwise proved to be robust across languages (see Rossi this issue a). Included were the following repair-related action types:

i. Seeking completion of something treated as missing from the original turn

ii. Seeking clarification or specification to solve a problem of hearing or understanding the original turn

iii. Seeking confirmation of one's hearing or understanding of the original turn In addition, two action types that go beyond repair were included:

iv. Treating the original turn as surprising, or counter to what the speaker would have expected

v. Questioning the acceptability or challenging the legitimacy or moral appropriateness of the original turn

All of these action types were deemed to have in common that they problematize the repeated turn in one way or another, making it relevant for the original speaker to respond in next turn.

Finally, an action type that is unrelated to repair was included on the grounds that it engages with the prior turn and potentially invites the original speaker to respond (cf. Schegloff 1997:527, also Persson 2015):

vi. Registering a prior turn, often the answer to a question 
The action analysis of the repetition turn was made in each case holistically, taking into account all sequential and multi-modal cues in the surrounding context. The way the repetition turn was responded to was often crucial in identifying its action, given that the recipient of the repetition turn is the best judge of what his/her interlocutor is expecting next. However, it was not possible to use this criterion mechanistically, as repetition recipients on occasion thwarted their interlocutors' actions, by, e.g., responding with a simple confirmation to a repetition that otherwise appeared to express surprise or a challenge (see also Jefferson 1972:310-2, Schegloff 2007:151ff). In these cases, it was necessary to rely wholly on cues in the sequential context, e.g., indications that participants were entertaining expectations to the contrary prior to the original turn (surprise) or following up with more explicit expressions of disagreement and other negatively-valenced talk after the response turn (challenge) (see also Rossi this issue a).

In the following we describe the basic structure of our other-repetition sequences and then present the most frequent pitch-accent types used for each of the repetition actions in question.

\section{STRUCTURE OF OTHER-REPETITION SEQUENCES}

All other-repetitions in our two English collections involve a common sequential structure, which is found across other languages as well:

(1) Schematic representation of structure of other-repetition sequences

1 A: Assertion, directive, question, or other action

2 B: Partial or full repetition, possibly followed by more talk

3 A: Uptake of repetition

The turn in line 1 we refer to as the 'original' turn, that in line 2 as the 'repetition' turn, and that in line 3 as the 'response' turn. The turn in line 1 can of course be partial itself (e.g., a single phrase or word), 
but in these cases it is usually possible to trace it back to a clausal structure in prior talk. The schema shown in (1) is the minimal structure; needless to say, there can be more topic-related talk following line 3. Cases in which other talk intervenes between lines 1 and 2 have also been included (see Rossi this issue a for more information).

\section{INITIATING REPAIR: OTHER-REPETITIONS DEALING WITH PROBLEMS OF HEARING AND UNDERSTANDING}

This is a macro-category capturing a set of three distinct actions through which speakers problematize what another has said on the grounds that they did not hear it properly or understand it sufficiently. Each action type makes a different kind of response relevant next.

(i) By repeating only part of the prior utterance in next turn, a speaker can seek completion of something treated as missing that prevents the utterance from being fully comprehensible. This can make it relevant for the original speaker to respond by filling in the missing part.

(ii) By repeating another's words in next turn, speakers can seek clarification or specification of the whole or part of the prior utterance and make it relevant for the original speaker to respond with, e.g., another version of what was said, a specification of an unclear referential form, or a clarification of what was meant.

(iii) By repeating what another has said in next turn, speakers can indicate that they are seeking confirmation of something they are relatively sure of having heard or understood. This makes it relevant for the original speaker to respond with a confirmation or disconfirmation of the repetition speaker's understanding.

In both varieties of English considered here, speakers make prosodic distinctions in otherrepetitions that correspond to these three types of hearing or understanding problem. However, pitch- 
accent type is not always a sufficient cue for the determination of which kind of repair-related action is being accomplished and thus what kind of response is due next.

Seeking completion of something treated as missing

Both varieties of English mark a problem due to something being incomplete in the prior turn with a similar prosodic configuration: the main, or focal, accent has level pitch and noticeable lengthening. Here is an example where this pattern can be observed: ${ }^{8}$

(2) "Abbie" (Lake_01.08). British English.

((Amanda has just mentioned that her friend Daisy has a chemistry exam the following Monday. Babs is now wondering if her roommate Lucas, who also studies chemistry, might know Daisy.))

1 Babs: I'll er ask LUcas; (0.2) if -

$2 \quad(0.2)$

2 Amanda: she's got long blonde HAIR=she's from 'CORNwall,

$3 \quad(0.4)$

4 Babs: $\quad[($ he shoul- $)=$

5 Amanda: [I'm living with her next [YEAR;

6 Babs: [he might 'KNOW her,

$7 \quad(0.8)$

8 Amanda: MAYBS-

$9 \quad(0.7)$

10 Amanda: she [lives with- Abbie=

11 Babs: $\quad[<<\mathrm{p}>$ maybs babes $>$,

$12 \rightarrow$ Amanda: I'm liv= ABbie's a chemist as 'WELL,

$13 \quad(0.3)$

14 $\Rightarrow$ Babs: $\quad$ ABbie:[:

15 Amanda: [COOperton;

$16 \quad(1.3)$

17 Babs: I'll ASK him. 
When Amanda mentions that Daisy lives with Abbie, who is also a chemist, Babs' hesitation (line 13) suggests that she is having trouble processing this turn. By now repeating the word Abbie with level pitch and lengthening its final syllable (line 14), Babs signals to Amanda that she needs some form of complementary information in order to know who is meant. Amanda immediately provides Abbie's last name in next turn (line 15). Babs subsequently returns to her promise to ask her roommate if he knows Daisy (line 17), thereby indicating that she now has the information that was missing. ${ }^{9}$

Figure 1. Praat picture of line 14 in example (2). ${ }^{10}$ Pitch-accent type: level.

Partial other-repetition with level pitch and lengthening from the focal syllable onwards is used by both British and North American English speakers to seek completion of something treated as missing in the prior turn. This is one of the few types of other-repetition where pitch contour is distinctive and potentially sufficient for identifying the action being accomplished.

Seeking clarification or specification for a problem of hearing or understanding

This subcategory is reserved for other-repetitions marking something just said as possibly misheard, as referentially unclear, or in general as difficult to understand. Here the two varieties use partially distinct pitch configurations for indexing such a problem.

In British English, lexical other-repetitions that seek clarification or specification for a problem of hearing or understanding have either a fall beginning high with respect to prior syllables (referred to here as a 'fall from high') or a rise-fall on their focal syllable. Optionally, there may be a final rise on 
the last syllable of the repetition. Here is an example of the most frequently attested pattern, a simple fall from high:

(3) "Six hundred-a" (Swimmers_04.39). British English.

((Three friends, Jack, Bob, and Chip, are talking about whether they will ever be able to pay off their debts.))

1 Chip: thAt reminds me to pAy off my uhm

$2 \quad(0.7)$

3 Chip: ((click)) (0.3) pay off my OVerdraft=

$4 \quad$ (which if I finally did) it'd be GOOD.

$5 \quad(0.7)$

6 Jack: ((laugh)) I'm never going to be ABle to.

$7 \quad(0.5)$

8 Jack: erm I [erm you know we're getting like

9 Chip: [YEAH you wIll, first=

$10=$ first year of the ARmy you get $<<\mathrm{p}>$ fucking $>$

$11 \quad(0.4)$

$12 \rightarrow$ Jack: $\quad$ yeah, that's TRUE. (0.2)

13 个you know you get um sIx hundred and sIxty QUID

14 for like first two weeks of sUmmer.

$15 \quad(0.8)$

16 $\Rightarrow$ Bob: $\quad$ thrEe hundred'n $\uparrow$ SIXty.

17 Jack: $\quad$ SIX hundred.

Jack, who has been in the army, concedes that it will be easier for him to repay his debts given that a sizeable sum of six hundred and sixty pounds is awarded for the first two weeks of military service (lines 13-14). After a delay, Bob, who has no experience of the army, now produces a repeat of what he has heard the sum of money to be: three hundred'n sixty (line 16). The main accent here is on sixty and it is delivered with a fall from high moving to low, as can be seen in Figure 2. Jack now repeats that part of his turn that Bob has misheard, with extra prominence on the number six (line 17). 
Figure 2. Pitch trace corresponding to line 16 in example (3). Pitch-accent type: fall from high.

Notice the pre-focal accent on three, which is also high in the speaker's range: this high pitch level is sustained as a plateau up until the focal syllable, which takes a small step upwards and then falls to low. We return to this typically British pattern below.

While all British English examples seeking clarification or specification for a problem of hearing or understanding have some kind of falling component in the pitch accent used in the repetition, nearly half of the North American English cases have instead rising pitch on or from the focal syllable. Here is a case in point:

(4) “Self-timer" (Cutie Pie_316.215). North American English.

((Jill has just jokingly suggested to her boyfriend that she could have someone take a picture of her holding the positive result of an Early Pregnancy Test (EPT) and later show it to their child.))

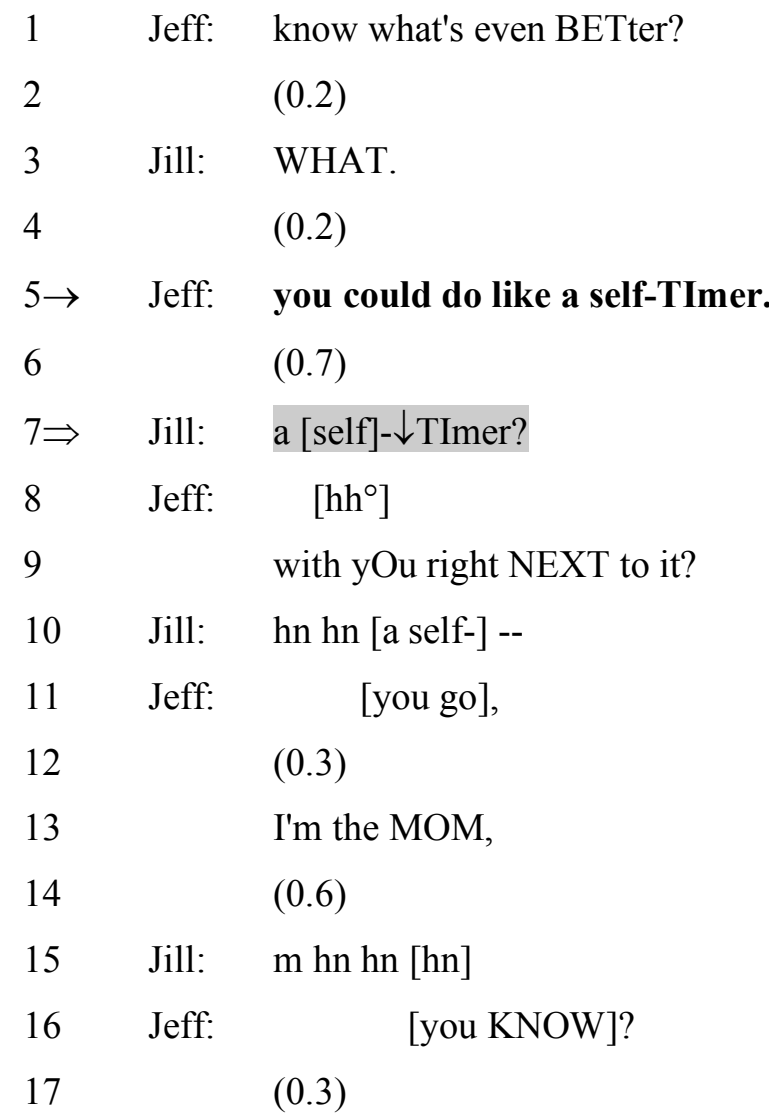


18 Jill: $\quad$ oh GOSH. $=$

19 Jeff: $=$ next to the reSULT?

20 Jill: .hhh [Oh GOSH.

21 Jeff: $\quad$ heh heh heh $\left[{ }^{\circ}\right.$ hhh

22 Jill: [RIGHT.

23 and I could even send it to ee-pee-TEE;

24 Jeff: $\mathrm{hh}^{\circ}$ yeah.

25 [eh heh heh heh]

26 Jill: [use it for ] ADvertising.

When Jeff proposes using a self-timer to take a picture of the positive EPT (line 3), there is initially no indication from Jill that she recognizes or understands what he means. Instead, after a significant pause, Jill repeats the noun phrase with a pitch contour that begins low on the focal syllable $(223 \mathrm{~Hz})$ and rises from there to high $(448 \mathrm{~Hz})$ (see Figure 3). In next turn Jeff now adds more detail by way of clarification (line 7), which leads to Jill's laughter and display of recognition (line 8).

Figure 3. Pitch trace corresponding to line 7 in example (4). Pitch-accent type: rise from low.

The pattern illustrated in Figure 3, a pitch contour beginning low on the focal syllable and rising to the end of the unit, is quite characteristic for North American English other-repetitions seeking clarification or specification for a problem of hearing or understanding. ${ }^{11}$

However, there is a second contour that is equally as widespread in North American English, one that involves a fall on the focal syllable, often preceded by a step-up in pitch or, as in (5), beginning high:

(5) "Slushies" (Farmhouse_32.20). North American English.

1 Donna: $\quad \uparrow$ you know what I'm rEally starting to like are those cOld 
$2 \quad(0.6)$ COFfee drinks $=$

3 Laura: =like the frappuCINos?

$4 \quad(0.5)$

5 Donna: I don't know (0.9) um is that just with ICE cubes,

$6 \rightarrow \quad$ I'm talking like SLUSHies.

$7 \quad(1.2)$

8 Donna: $\quad<<\mathrm{p}>\downarrow$ they're [like $\downarrow>=$

9 $\Rightarrow$ Michelle: $\quad$ [个SLUSHies;

10 Donna: =SL:USHy::

$11 \quad(0.5)$

12 Laura: [O::H.

13 Michelle [like PEAberry's?

14 the FROzen bears?

15 Donna: yEah.

$16 \quad(0.7)$

17 Michelle: my sister LOVES those.

When Donna proclaims her love for cold coffee drinks (lines 1-2), Laura guesses that she is referring to frappucinos (line 3). But Donna insists that she means something known as slushies (line 6). After a lengthy pause, and in partial overlap with Donna's turn continuation, Michelle now repeats slushies, with a pitch contour beginning high on the focal syllable and falling to a mid-point in her pitch range. Michelle's contour can be seen in Figure $4 .{ }^{12}$ Donna goes on with a characterization of the drinks as slu:shy:: (line 10), whereupon Michelle actively displays candidate recognition (lines 14-15), now confirmed by Donna (line 15).

Figure 4. Pitch trace corresponding to line 9 in example (5). Pitch-accent type: fall from high. 
Focal rises and focal falls are approximately equally distributed in North American English otherrepetitions seeking clarification or specification for problems of hearing and understanding. This contrasts starkly with British English, where focal falls predominate to the exclusion of focal rises.

\section{Seeking confirmation or disconfirmation}

With this category of other-repetition, the repetition speaker assumes an epistemic stance of greater certainty (by comparison with repetitions seeking clarification or specification) that what $\mathrm{s} / \mathrm{he}$ is repeating is indeed what the interlocutor said or meant. At the same time the speaker indicates that there is some remaining uncertainty, making relevant a confirmation (or disconfirmation) by other. There is no suggestion that what has been said runs counter to expectation or stands in need of correction.

Somewhat surprisingly, the two English varieties under consideration here use many of the same focal pitch contours on this type of repetition as for problems of hearing and understanding that require clarification or specification. In British English, we find primarily falls from high such as in the following extract:

(6) "Whole of panel” (Drama_10.25). British English.

((A group of drama students are discussing an upcoming play competition at their institute.))

1 Doug: one DRAFT=whO reads that one DRAFT.

$2 \quad(0.3)$

$3 \rightarrow$ Carl: $\quad$ the whOle of PANel [can read it.

$4 \Rightarrow$ Doug:

5 Angela:

6

7 Carl: ju- just li:ke they read any other PLA:Y that people applY with. 
Doug's query as to who reads the drafts that are submitted for the play competition (line 1) treats Carl as the party most knowledgeable in this matter. Carl's answer is authoritative: the drafts are read by the whole panel (line 3). Coming in at a point where the thrust of Carl's turn is recognizably complete (after the whole of panel), Doug now repeats this answer in next turn (line 4). His repetition turn begins high on the pre-focal accent whole $(140 \mathrm{~Hz})$ and falls on the focal accent panel to his baseline $(90 \mathrm{~Hz})$, covering a range of 7.6 semi-tones. Carl indirectly confirms Doug's understanding in his next turn (line 7).

In North American English, by contrast, it is rising focal accents that predominate on other repetitions that seek confirmation: they massively outnumber focal falls. Here is a typical example:

(7) "Maybe more now" (Farmhouse 20.58). North American English.

((Laura, her mother, a friend Michelle, and a neighbor Donna are talking about their struggles with weight watching.))

1 Laura: and $\uparrow$ SOME PEOPLE: (.) can DO that.=

$2 \quad=\downarrow$ some people can put aside their piece of PIZza

3 and eat their salad and(h) enj(h)oy it LAter,

4 but I [frankly could N(h)OT(h)._huh

5 Donna: [eh heh heh heh heh

$6 \quad(0.2)$

7 Laura: [and I KNOW that.

8 Michelle: [well it depends on what TYPE of pizza i(h)t i(h)s.[(does dudn't it]

9 Laura: [yea:h

$10 \quad(0.4)$

11 Laura: Pizza Hut PIZza I couldn't.=

12 Donna: =(I) think it's AGE too.

14 Donna: $\quad<$ p $>$ I think. $>$

15

16 Laura: WHY;= 
18

$19 \rightarrow$ Donna: $\quad *$ maybe more NO[W.

donna: *nods several times

$20 \Rightarrow$ Laura:

21

$\begin{aligned} & *(0.4) \\ \text { donna: } & * \text { nods }\end{aligned}$

22 Donna:

$<<$ p $>$ than I would've $>$

24 Donna:

25 Laura:

26

27 Donna:

28

29 Laura:

30

heh heh heh

j(h)ust- I don't know.

(.)

well my jeans still FIT;

\section{[maybe more $\downarrow$ NOW,}

would have been like YOU up till last y(h)Ear. eh heh heh[heh

[eh heh

so I guess when they stop fitting I might have to DO that.

When Donna claims that being older makes it easier to resist overeating (line 12), Laura solicits an account, asking directly if Donna means she herself can do this now (line 17). ${ }^{13}$ Donna's reply is maybe more now, which Laura repeats, in terminal overlap, in next turn (line 20). We can assume that Laura has heard and understood Donna's reply, since she has just reformulated it herself as could you do that now (line 17). So when Donna responds with head nodding and an ever so slight qualification of this reformulation (line 20), Laura's immediate repeat is not seeking clarification or specification but is rather simply seeking confirmation of what Donna has said. Donna's head nods in the ensuing pause confirm this interpretation. The focal accent on now in Laura's repeat begins low (around 166 $\mathrm{Hz}$ ) and rises to a point as high as at the beginning of her turn (around $210 \mathrm{~Hz}$ ), covering a range of 4.7 semi-tones.

Table 1 summarizes the use of pitch contour for producing the three types of repair initiation achieved through other-repetition: 
Table 1. Most frequent pitch contours for major other-repetition actions

In both varieties of English, other-repetition that seeks completion is distinguished from the other kinds of repair initiation through a level pitch contour. Yet neither variety systematically distinguishes seeking clarification or specification and seeking confirmation by focal accent type. British English speakers use the same pitch accent (fall from high) for both. North American English speakers prefer a different accent type (rise from low) but it too is used for both other-repetition actions.

This finding naturally leads to the following question: If different types of response are made relevant next, how are the two types of other-repetition - seeking clarification or specification and seeking confirmation - distinguished? The answer appears to lie not in pitch contour, but in the transition timing of the repetition turn with respect to the prior turn. All the British and North American English cases of seeking clarification or specification are noticeably delayed: they do not set in immediately at the TRP of the prior turn but come after a gap of silence ranging from, e.g., 0.8 sec. and $0.7 \mathrm{sec}$. in examples (3) and (4) to $1.2 \mathrm{sec}$. in example (5) (see Kendrick 2015). This contrasts sharply with other-repetitions that merely seek confirmation: in both varieties: these routinely come without a delay. Arguably this is due to the fact that speakers who are relatively certain of what has been said or meant do not need to search for recognition of the prior turn's meaning or action nor provide the other with an opportunity for self-repair (Schegloff, Jefferson, Sacks 1977; Kendrick 2015). They merely need the other to confirm their understanding, which is what we find happening in (6) and (7).

\section{BEYOND INITIATING REPAIR: OTHER-REPETITIONS DEALING WITH PROBLEMS OTHER THAN HEARING AND UNDERSTANDING}


We turn now to two subcategories of other-repetition that do more than request repair strictu sensu. First, speakers can repeat what their interlocutor has just said in a way that indicates that it goes against what they expected: in such cases the repetition serves as a display of surprise (see also Wilkinson and Kitzinger 2006), making it relevant for the interlocutor to account for or explain the clash of expectations with reality (see also Selting 1996). Second, speakers can imply with otherrepetition that what the interlocutor has just said is wrong, unacceptable, or morally questionable: in these cases, the repetition could be said to mark a display of disbelief and to serve as a challenge (see also Benjamin and Walker 2013). Displays of disbelief and challenges make it relevant for the recipient to justify themselves in subsequent talk.

This said, the distinction between using lexical repetition to display surprise and using it to do disbelief or a challenge is sometimes cloudy, and mixed cases are not infrequent. On occasion recipients stonewall the displayed emotive tones of the repetition altogether and simply confirm what has been said (see also Jefferson 1972:310-2, Schegloff 2007:151ff), thereby removing the possibility of using next-turn proof procedure to distinguish repetitions doing surprise from those doing disbelief or challenge (see also Heritage 2012b:80). In the following discussion, we have chosen what we believe to be clear cases of these two categories to illustrate their most common prosodic contours.

\section{Other-repetitions treating the original as a source of surprise}

Much as studies of affect and emotion in everyday interaction have shown (Peräkylä and Sorjonen, eds., 2012), emotions such as surprise are not (or not only) visceral reactions but social displays (see, also Goffman 1978 and Wilkinson and Kitzinger 2006). Displaying surprise in conversation becomes relevant, for instance, if speakers are publicly confronted with something that clashes with their prior expectations. Sometimes an appreciation of unexpectedness can be part of what the original speaker's talk has been building up to, for example, in a telling (Wilkinson and Kitzinger 2006). Or a speaker's 
expectations can become apparent, e.g., through the way a question is asked or a candidate understanding is formulated. If an interlocutor produces information that runs against these expectations, speakers can use other-repetition to make a display of surprise. Here is an example where we observe this happening:

(8) "She died" (HumanitiesStudents-b_13.08). British English.

((Gerda, who is Canadian, has been explaining to Dirk how she brought some of her favourite records with her when she came to England to study and left them at her grandmother's. Now she is having trouble remembering which ones they were.))

1 Gerda: it's been Ages since I looked at them. Uhm-

2 Dirk: whEn did you bring them when you first came OVer.

3 Gerda: yeah. ocTOber.

4 Dirk: (bEen) there a WHILE.

5 Gerda: there's one of the RECord players though,

$6 \quad$ it's kinda SITting [(there)

7 Dirk: [have you been ROUND there.

8 when was the last time you went to SEE her (.) y'grandma.

$9 \quad(1.5)$

10 Gerda: SUMmer.

11 Dirk: SUMmer.

$12 \quad(0.2)$

13 oh so it WASn't that long ago.

$14 \rightarrow$ Gerda: but um (.) yeah she died this SUMmer; =

15 and then I came- I think the last time I[:

$16 \Rightarrow$ Dirk:

[oh she- (.) she $\uparrow \downarrow D I E: D$.

17 Gerda: yeah.

18 Dirk: oh right I didn't I thought you were going like (.) to VISit.

19 Gerda: no um-

20 Dirk: oh RIGHT= I GET you.

21 Gerda: the one in CANada's alive. $=[$ the one $=$

22 Dirk: [yeah.

23 Gerda: =in ENGland uhm died this summer. 
Notice that the question Dirk asks in line 8 when was the last time you went to SEE her (.) y'grandma is formulated with a reference to the grandmother that assumes she is still alive. When Gerda disabuses Dirk of this assumption in a by-the-way fashion (line 14), Dirk repeats the unexpected information, after a slight delay, as a source of surprise: oh she- (.) she DIED (line 16). In subsequent talk, after Gerda's confirmation (line 17), Dirk goes on to state what he mistakenly thought (line 18) and Gerda continues with an explanation that goes some way towards exonerating him for the mistake. The other-repetition is thus treated by both parties as displaying surprise due to a conflict between expectation and reality.

The focal pitch configuration used on the repetition in (8) is a high rising-falling contour on the focal syllable died (see Figure 5).

Figure 5. Pitch trace of line 16 in example (8). Pitch-accent type: high rise-fall.

The falling part of the high rise-fall contour on die: $d$ has a pitch span that covers 11 semitones. Note the presence of $o h$ as a preface to the repeat speaker's turn. This $o h$ is also delivered with a high risefall peak (in Reber's terms it is an 'extra high and pointed' oh (2012:92)) and in this sequential context is a further index of the surprise displayed by Dirk's repetition turn.

In the present data set, a high rise-fall focal contour is one of the two most frequent contours found on British English other-repetitions making displays of surprise. The other highly frequent contour is one we have encountered before: a fall from high on the focal syllable (with optional rising pitch at the end of the unit). This is the contour attested in the following case:

(9) “Landrover" (Lake_04.50). British English.

((Two college friends speaking about moving furniture to Babs' new apartment. The reference in line 1 is to a set of shelves.)) 
1 Amanda: yeah but $\uparrow$ how big IS it. $\uparrow$ (.)

2 because like surely you can stIck it (0.4) in a CAR.

$3 \quad(0.4)$

4 Babs: NO:, (.) you could tie it to the [top of a LANdrover,=

5 Amanda: [are they-

$6 \rightarrow$ Babs: $\quad=$ but you couldn't fit it IN the Landrover.

7

$8 \Rightarrow$ Amanda:

you $\uparrow \mathrm{cOuldn}$ 't fit 'IN a Landrov[er. ((raised eyebrows))

9 Babs:

[NO. ((lateral head shake))

10

amanda: *looks away, lowering corners of mouth

11 Amanda: <p, creaky $>$ OH.>

Prior to this exchange, Babs has announced that she needs someone to help her move a large bookshelf, whereupon Amanda states that she assumes it would fit in a car. But Babs nixes this assumption, explaining that the shelf has six stacks which she can no longer take apart. In line 1 Amanda now implies that the shelf cannot be that big and once again claims that Babs can just 'stick' it in a car (line 2). Thus, when Babs now denies this and states that the bookshelf might fit on top of a Landrover but not in it (lines 4 and 6), this (again) counters Amanda's expectations: even a car as large as a Landrover would not be able to accommodate the bookshelf. Amanda displays her surprise through a delayed full repeat of the second component of the turn, delivered with raised eyebrows (line 7). ${ }^{14}$

Amanda's repetition has a high-pitched plateau, characteristic of British English, that begins on couldn't, the first accented syllable of the repetition turn $(266 \mathrm{~Hz})$, and falls from the focal syllable, in, to low $(156 \mathrm{~Hz})$, covering a range of 9.1 semitones. Recall that the same high peak/plateau + focal falling contour was also encountered on other-repetitions seeking clarification or specification (compare Extract (3) above). Although the latter are accompanied by significant delays, the timing of other-repetition in general is not a reliable indicator of 
whether the repeat speaker is requesting repair or not, since displays of surprise can also have significant delays (as here). Ultimately then, the interpretation would seem to depend on whether there is evidence in prior talk that the repetition speaker had different expectations and/or on whether there are accompanying non-verbal signs of surprise such as raised eyebrows.

Moreover, the presence of $o h$ is a good indication that the speaker has been disabused of an unwarranted assumption.

The situation is only slightly different in North American English. Here, too, we find focal falls from high on displays of surprise. However, even more frequent in North American English displays of surprise are contours that rise from low. Here is a case in point:

(10) “Thursday night” (Nb 006_6.743). North American English.

((Emma has just called her sister Lottie on the phone. Earl is Lottie's husband.))

4 Emm: $\quad=$ oh: HI: honey=we haven't gotten toGETher have we.

$5 \rightarrow$ Lot: $\quad$ Oh:: gosh NO:

$6 \rightarrow \quad$ let's SEE: $(0.2)$ THURS:day night I went in town=

$7 \quad$ I came back FRIday=it was LA:TE,

$8 \quad(0.8)$

9 $\Rightarrow$ Emm: $\quad$ Oh you went in $\downarrow$ THURSday ni:ght?

10 Lot: $\quad$ yEa:h; oh EARL had to get some stUff for: uh:::w

11 u- uh::m (0.2) working on a PICture=

12 so I had to go up there'n GET it ['n : : ]

13 Emm: [n you wor]ked Thursday TOO:?

$14 \quad(0.2)$

15 Lot: $\quad$ yeah $(0.2)$ yEa::h? Thursday NIGHT I went uh

$16 \mathrm{hO}[: \mathrm{me}$.

$17 \mathrm{Emm:} \quad[\mathrm{u}-\mathrm{Oh}]::[\mathrm{af}] \mathrm{ter}$ th]e.

18 Lot: [ye] b o u]t one o'CLOCK w[e left] here.]

19 Emm: $\left.\quad\left[\downarrow_{\mathrm{oh}}: \mathrm{m}\right] \mathrm{y}: \mathrm{G}\right] \mathrm{OS}::: \mathrm{H} . \downarrow$

$20 \quad(0.3)$

21 Lot: en 
$23 \mathrm{Emm}$ WELL it's been beautiful weather,

Emma's first topic in this call is the negative observation that she has not seen much of her sister (line 4); this is an incipient complaint, which moves Lottie to recap her recent activities. She reports that she went into town on Thursday night and did not return until late Friday (lines 6-7). It is this information that Emma, after a significant pause, receipts with oh and a repeat: you went in $\downarrow$ THURSday night? (line 9). From what transpires, it is clear that Emma finds this hard to reconcile with what she knows, namely that Lottie usually works Thursdays (line 13) and that it would be difficult for her to do both. Lottie treats Emma's repeat as displaying surprise: after a confirmation, she explains that she had to go into town to pick up something for her husband (lines 10-12) and that she went at night (lines 15-16), leaving about one o'clock (line 18). Emma's multiple oh prefaces (lines 9, 17, 19) track her gradual understanding of how something she did not expect to happen actually came about. The focal pitch accent Emma uses on her repeat begins relatively low on Thursday $(226 \mathrm{~Hz})$ and rises very high (to $430 \mathrm{~Hz}$ ), covering altogether a span of 11.1 semitones.

Just as prevalent as contours rising from low for displays of surprise in North American English are, however, high rising-falling contours, as illustrated in the following:

(11) "Welcome home" (SF2_00.46). North American English.

((Mark has called his friend Bob to tell him that he has heard Bob is having a party but that he (Mark) doesn't know anything about it.))

1 Bob: didn't we TELL you?

$2 \quad(0.4)$

3 Mar: $\quad$ NO: whEn t-t-dju uh, you mEt- ${ }^{\circ}$ hhh

4 个a LONG time ago someone mentioned something about having a

5 go:ing aWAY party. 


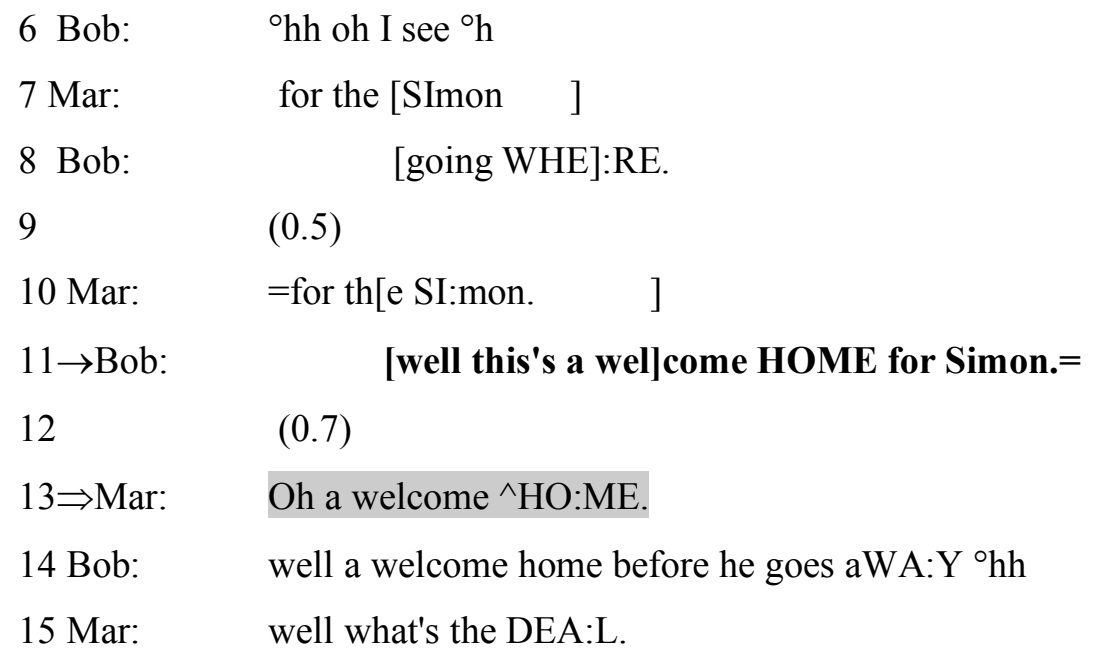

As Mark explains in lines 4-5, 7 and 10, he has heard about a going-away party for their mutual friend Simon; he surmises that this is the party that Bob is now said to be throwing, although he has not received an invitation to it. But Bob disabuses him of this by announcing that the party being thrown will be a welcome home for Simon (line 11). After a significant delay, Mark repeats this information with an oh preface (line 13). Note that Bob now provides an explanation for the clash of expectations in next turn: the plan is to welcome Simon home before he goes away (again). In this exchange, Bob is clearly the epistemic authority $[\mathrm{K}+]$ : he is the one who informs his unknowing [K-] partner Mark about a state of affairs in the world. Mark's repetition turn, Oh a welcome HOME, is produced with a strong rising-falling accent on the focal syllable home. The rise extends from $170 \mathrm{~Hz}$ to $218 \mathrm{~Hz}$, covering a span of 4.3 semitones; the fall reaches the bottom of Mark's pitch range $(109 \mathrm{~Hz})$, covering a span of 12 semitones.

In sum, the focal contours found on North American English other-repetitions that display surprise, like their British English counterparts, are also not specific to this category but are patterns encountered on other types of other-repetition. Falls from high are also found on repetitions seeking clarification or specification (cf., e.g., (5) "Slushies"); the contour rising from low of (10) is also found, e.g., on repeats that seek confirmation (e.g., (7) "Maybe more now"); and the strong rising-falling contour of (11) is similar to those used for disbelief and challenges 
(see below). We conclude that in North American English, too, other factors must be in play allowing recipients to ascribe the specific action of displaying surprise to these other-repetitions. One of these is undoubtedly pitch span: the falls from high as well as the rises from low in North American English tend to have a wider pitch span for displays of surprise than for the initiation of repair. This is in line with the findings for all other languages studied in this special issue. Moreover, like in British English, there is often prior talk that has implied expectations to the contrary and/or the speaker uses an oh preface (see also Local 1996).

\section{Other-repetitions marking disbelief or a challenge}

This category of other-repetition has been well described by Benjamin and Walker (2013), who point out that the repetition speaker is treating the repeated material as wrong, inacceptable, or inappropriate. There is typically a moral tinge to this kind of repetition: the original speaker is being called upon to correct, modify, or justify their prior claim or behavior. Benjamin and Walker identify a specific pitch contour characterizing these repeats: a high rise-fall (HRF) movement starting on the last accented syllable, with the rising portion averaging a range of 8.2 semitones and the falling portion averaging a range of 12.4 semitones (2012:114). Our study corroborates these findings in many ways. However, it also relativizes them by showing that HRFs are also used to display surprise (see above) and that other focal pitch contours can mark disbelief and challenge as well.

In fact, in our collection of British English other-repetitions that function as challenges, it is focal falls from high that are slightly more frequent than high rising-falling contours. Here is a case in point:

(12) “Megan" (Swimmers_01.23). British English. 
((Bob is telling his friends Jack and Chip about the amateur play he will soon be starring in at school.))

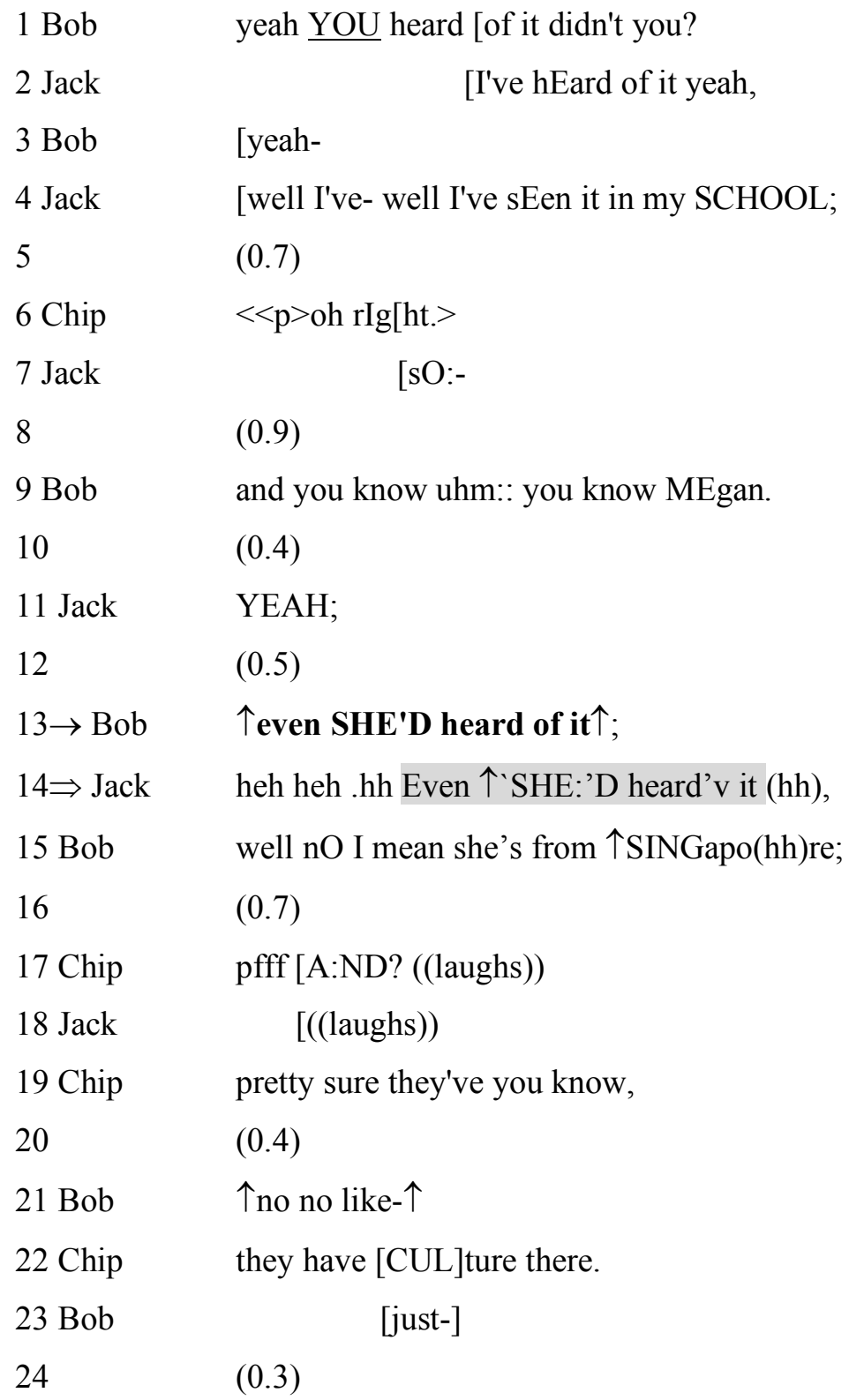

25 Bob I'm not being u::hm I'm not being FUNny.

Bob is trying to convince his friends that the play he is starring in is well known: as testimony to this, he notes that even a mutual friend, Megan, has heard of it (line 13). Jack now produces a number of aspiration particles that come off as a snicker and then repeats this line, Even TSHE: 'D heard'v it, followed by an outbreath (line 14), whereupon Bob - rather than re-doing what he has said or simply confirming it - moves immediately to defend himself (line 15). ${ }^{15}$ This 
is a good indication that Bob has heard Jack's repetition as a challenge. Figure 6 shows its focal pitch contour:

Figure 6. Pitch trace of line 14 in example (12). Pitch-accent type: fall from high.

The focal syllable she' $d$ begins slightly higher than the prior two syllables ${ }^{16}$ and drops to the bottom of the speaker's pitch range, spanning a range of approximately 16 semitones. There is no acoustic indication, nor auditory impression, of a prior rising glide on the syllable she'd.

Yet this is not to claim that British English other-repetition challenges lack high rise-fall contours; on the contrary: HRFs are nearly as frequent as falls from high in our collection. Here is an example:

(13) “Body hurts" (Grass_00.05.30). British English.

((A group of six classmates is sitting in a circle on the campus grass $)$ )

1 Cor: +o:o:o:o:nheh!

cor: $\quad$ +slowly leans over to rest head on ground

2 Bet: are you al'RIGHT;

$3 \rightarrow$ Cor: $\quad *$ my BODy hUrts.

bet: $\quad$ *reaches over to stroke Corinne's back

$(0.9)$

$4 \Rightarrow$ Bet: $\quad{ }^{* \wedge}$ YOUR body hurt(h)s(hh).

bet: $\quad$ *gestures histrionically with left arm

dia: $\quad$ •begins to yawn, raising papers to cover mouth

5 Bet: $\quad<<$ all, $\mathrm{p}>$ heh joking it's fine $>$.hhh $\wedge(0.9)$

dia: $\quad$ Afinishes yawn and lowers papers

6 Dia: I might have a NAP. hhhh 
When Corinne begins to groan and lean over to rest her head on the ground, Beth solicitously asks if she is okay (lines 1-2). Corinne's reply is that her body hurts, whereupon Beth begins to stroke her back. But Beth then suddenly reverts from other- to self-attentiveness, now exclaiming YOUR body hurts (line 4, note the stress shift to YOUR) accompanied by a histrionic arm gesture (line 4). The implication here is 'what about mine?'. The force of Beth's utterance as a challenge is further revealed by the fact that she subsequently rescinds the challenge by stating that she is joking (line 5). At the same time, Diane begins a prolonged yawn, only partially camouflaged by her papers. Thus, Corinne's two classmates subtly join forces to challenge her right as the only one to be tired and in pain. The main accent in line 4, now on your, begins relatively low (200 $\mathrm{Hz})$ and rises to high $(329 \mathrm{~Hz})$ before falling to low pitch at the end of the unit $(147 \mathrm{~Hz})$, covering a range of 13.9 semitones altogether.

High rise-falls are only slightly less frequent in the data than focal falls from high on British English repetitions that mark disbelief or a challenge. Both can be optionally followed by a final rise at the end of the turn.

In the North American English sub-collection we also encounter similar high rise-falls (with or without a final rise) on repetitions marking disbelief or a challenge. But just as frequent in North American English repetitions functioning as challenges are contours that rise from low. Here is a case in point:

(14) “Just talking” (Cutie Pie_377.68). North American English.

((From a long-distance telephone call between Jeff and his girlfriend Jill. Jill is out of town visiting a friend.))

1 Jeff: $\quad$ so you guys have been having a good TIME,

2 Jill: unHUNH=,

3 SUCH a good time.

4 it's SO good to sEe her.

5 Jeff: staying up LATE, 


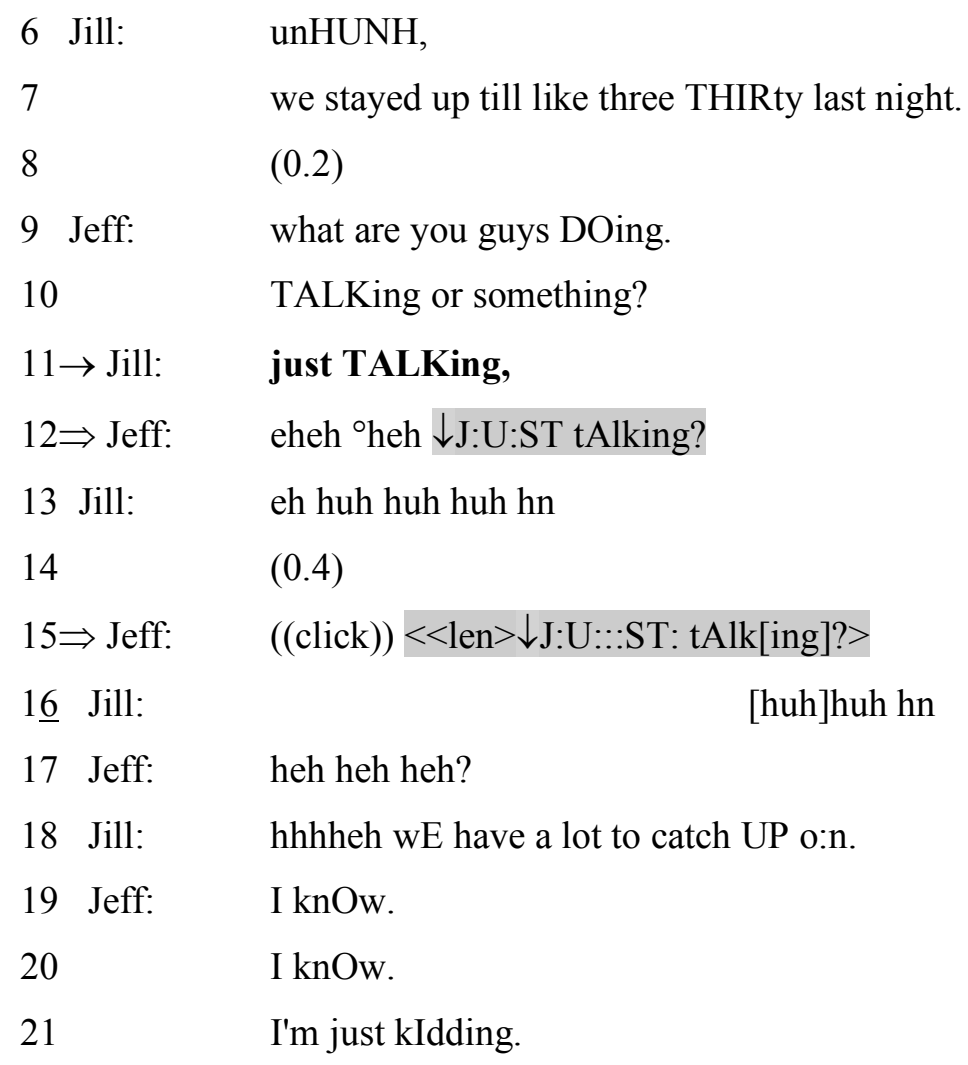

Notice that in repeating Jill's answer from line 11, Jeff shifts the main accent from talking to just: this contributes to the implication that that there may have been more going on than talking. At the same time he drops his pitch at the beginning of just (to $88 \mathrm{~Hz}$ ) and from there produces a steady rise on subsequent syllables (up to $224 \mathrm{~Hz}$ ). This contour covers a range of 16.2 semitones. Jeff's repeat is a challenge, reiterated again in line 15. After some giggling, Jill acknowledges as much when she moves in next turn to defend herself with we have a lot to catch up on (line 18).

To recap, North American English repetitions that function to mark disbelief or a challenge are as likely to be delivered with a pitch contour rising from low as with a high risingfalling contour (with or without final rising pitch). This means that Benjamin and Walker (2013) are right when they claim that HRFs can lend a case of other-repetition the moral implication that what has been said is inappropriate or inacceptable. But HRF is not the only contour that accomplishes such work: falls from high in British English as well as strong rising contours in 
North American English can do the same. Moreover, in both varieties, HRFs are also found on other-repetitions that display simple surprise, without any implication of moral inappropriateness.

Table 2 presents in overview the most frequently used contours in the two varieties for other-repetition actions that go beyond repair initiation.

Table 2. Most frequent pitch contours for major other-repetition actions

Here, too, we might ask what it is that allows recipients of repetition turns to recognize challenges and distinguish them from displays of surprise if pitch contour does not help. Arguably, one non-prosodic dimension is epistemics, or how much access to knowledge repetition speakers are displaying with their repeat. With displays of surprise, repetition speakers are ostensibly buying into what the other has said on the grounds that the other is the authority: this is often reflected in their use of the change-of-state particle $o h$ (as in Extracts 8, 10, and 11). With challenges, on the other hand, recipients convey from a stance of greater epistemic access (in the sense of Robinson 2013) that something is wrong or unacceptable about what the other has said: in these cases, use of the change-of-state particle $o h$ is inappropriate (notice its absence in Extracts 12, 13, and 14).

\section{OTHER-REPETITIONS THAT REGISTER A PRIOR INFORMING}

Besides initiating repair and going beyond the initiation of repair to display surprise or disbelief, recipients can use other-repetition to simply register what has been said. No further action is made conditionally relevant by such a repetition, although occasionally a confirmation may be provided (see Schegloff 1997:527; Persson 2015). Other-repetitions that accomplish registering 
have a similar prosodic design in the two varieties of English: the pitch contour is typically a low and narrow fall, as in this excerpt from Extract (8):

(15) "Summer" (Humanities Students-b_13.08). British English.

8 Dirk: when was the last time you went to SEE her (.) y'grandma.

$9 \quad(1.5)$

$10 \rightarrow$ Gerda: $\quad$ SUMmer.

$11 \Rightarrow$ Dirk: $\quad$ SUMmer.

$12 \quad(0.2)$

13 oh so it WASn't that long ago.

What Dirk is repeating here is the answer that Gerda has just provided to his prior question about when she last went to see her grandmother (line 8). With this repetition of summer (line 11) Dirk is not assuming a stance of knowing more than Gerda (in fact, she is the epistemic authority), nor does Gerda's reply conflict with any assumptions Dirk has intimated having. Instead, Dirk's repetition merely acknowledges what Gerda has said, subsequently using it as a basis from which to infer that the visit was not that long ago (line 13). Dirk's repetition of Gerda's summer begins immediately and is done with a low, slightly falling contour, as can be seen in Figure 7:

Figure 7. Pitch trace of line 11 in example (15). Pitch-accent type: Low fall.

Such a low, narrow fall is quite distinct from the fall-from-high contours seen earlier and is a potentially distinctive cue to the action of registering in both British and North American English other-repetitions. 
Table 3. Most frequent pitch contours for major other-repetition actions

Registering repeats typically mirror the focal contour of the prior informing, while at the same time being lower and more compressed in terms of pitch. This is a further distinctive hallmark of the category.

\section{SUMMARY AND CONCLUSION}

Taken together, Tables 1-3 summarize the findings for pitch contours in British and North American English other-repetitions. A number of conclusions can now be drawn from these findings.

\section{i. Repair initiation seeking completion and registering are the only other-repetition actions} associated with distinct focal pitch contours in the two varieties (see Tables 1 and 3 ). The level pitch contour and the low fall contour are found exclusively for these two actions respectively, and they are the same in both varieties.

ii. Aside from these, other-repetition actions are often associated with more than one focal pitch contour in the two varieties (see Tables 1 and 2). For example, in North American English, repair initiation seeking clarification or specification can have two quite distinct contours as can a display of disbelief or challenge; a display of surprise can have three distinct focal contours. In British English both displays of surprise and of disbelief or challenge are associated with two different focal contours. 
iii. In both varieties the same contour can be used for different types of other-repetition action (see Tables 1 and 2). In British English, for instance, focal falls from high ( \pm final rise) occur in four different action categories. Likewise, in North American English, focal rises from low occur in four different categories. In both varieties, high rise-falls (HRFs) are found with displays of surprise as well as with displays of disbelief and challenge.

$i v$. The same action can have different contours in the two varieties (see Tables 1 and 2). For instance, in British English, repair initiations seeking confirmation have primarily focal falls from high, while in North American English they are more likely to have focal rises from low.

v. Rising contours appear more frequently overall in North American English than in British English other-repetitions. In British English other-repetitions, rising pitch can occur non-focally, at the end of the turn (see Figure 6), but in North American English, it is associated with the focal accent (see Figure 3). Moreover, North American rises on other-repetitions are typically accompanied by a step-down in pitch to the focal syllable, which contributes to making the rising component more salient.

vi. Falling contours are more frequent overall in British English than in North American English other-repetitions. In repetition turns with focal falls from high, the high pitch typically begins on pre-focal accents early in the turn. This high pitch is maintained up to the focal syllable, creating a high plateau effect (see Figure 2). Although focal falls from high are also encountered in North American English other-repetitions, the step-up to high pitch begins on the focal syllable; it is not part of a high plateau begun earlier in the unit. 
These findings are revealing with respect to regional preferences for pitch contours in British and North American English other-repetitions, but -- with the exception of the actions of requesting completion and registering -- they do not account for how recipients know whether someone who repeats what has just been said is initiating repair on it or going beyond repair to display surprise or disbelief at it. To appreciate how this happens, we must take more than pitch contour into consideration. Table 4 shows a fuller picture:

Table 4. Prosodic and non-prosodic cues to other-repetition actions in English

Table 4 lists both prosodic and non-prosodic features observed in the data that play a role in distinguishing other-repetition actions. In addition to pitch contour, which appears to be distinctive only for the actions of seeking completion and registering, other prosodic factors such as pitch span and volume enter in, e.g., for distinguishing other-repetition actions that initiate repair from those that go beyond repair: the latter tend to have a wider pitch span and greater loudness than do the former. Within the category of repair initiation, transition timing helps distinguish other-repetitions that seek clarification or specification from those that seek confirmation: the former are delayed, the latter are not. Non-prosodic factors (verbal, visible, contextual) also play a role here, with other-repetitions seeking confirmation involving greater epistemic access (the repetition speaker is partially $[\mathrm{K}+]$ ) than those seeking clarification or specification. Within the category of actions that go beyond repair, epistemic access is crucial in distinguishing displays of surprise from displays of disbelief and challenges. Repetition speakers who display surprise are treating the other as having greater epistemic access, with $o h$-prefacing signalling that they have now been informed of something they did not know before (Heritage 1984). With challenges and displays of disbelief, on the other hand, repetition speakers are 
constructing themselves as $[\mathrm{K}+]$ enough to judge that what the other has just said requires correction; oh-prefacing does not occur. And finally, the contribution of visible cues such as raised eyebrows to the display of surprise should not be underestimated. The picture is thus a complex one but one not lacking in systematicity.

\section{ACKNOWLEDGMENTS}

I am grateful to two anonymous reviewers for constructive criticism and especially to Giovanni

Rossi for help in improving this article. All remaining errors are my own.

\section{REFERENCES}

Benjamin, Trevor \& Traci Walker (2013). Managing problems of acceptability through high rise-fall repetitions. Discourse Processes 50(2): 107-138.

Bolinger, Dwight (1998). Intonation in American English. In Daniel Hirst \& Albert di Cristo (eds.) Intonation Systems. A survey of twenty languages, 45-55. Cambridge, UK: Cambridge University Press.

Couper-Kuhlen, Elizabeth (1986). An Introduction to English Prosody. London: Edward Arnold \& Tübingen: Max Niemeyer.

Couper-Kuhlen, Elizabeth (2012). Some truths and untruths about final intonation in conversational questions In Jan P. de Ruiter (ed.), Questions: Formal, functional and interactional perspectives, 123-145. Cambridge, UK: Cambridge University Press. 
Couper-Kuhlen, Elizabeth \& Dagmar Barth-Weingarten (2011). A system for transcribing talk-ininteraction: GAT 2. English translation and adaptation of Selting, Margret et al: Gesprächsanalytisches Transkriptionssystem 2. Gesprächsforschung Online 12: 1-51. Cruttenden, Alan (1986/1997). Intonation. Cambridge, UK: Cambridge University Press.

Crystal, David (1969). Prosodic Systems and Intonation in English. Cambridge, UK: Cambridge University Press.

Geluykens, Ronald (1988). On the myth of rising intonation in polar questions. Journal of Pragmatics 12(4):467-85.

Goffman, Erving (1978). Response cries. Language 54: 787-815.

Grice, Martine \& Stefan Bauman (2007). An introduction to intonation - Functions and models. In Jürgen Trouvain \& Ulrike Gut (eds.), Non-native prosody: Phonetic description and teaching practice, 25-52. Berlin, New York: Mouton de Gruyter.

Heritage, John (1984). A change-of-state token and aspects of its sequential placement. In J. Maxwell Atkinson \& John Heritage (eds.), Structures of Social Action. Studies in Conversation Analysis, 299-345. Cambridge, UK: Cambridge University Press.

Heritage, John (2012a). Epistemics in action: Action formation and territories of knowledge. Research on Language and Social Interaction 45(1): 1-29.

Heritage, John (2012b). Beyond and behind the words: Some reactions to my commentators. Research on Language and Social Interaction 45(1): 76-81.

Hirschberg, Julia \& Gregory Ward (1995). The interpretation of the high-rise question contour in English. Journal of Pragmatics 24(4): 407-12.

Jefferson, Gail (1972). Side sequences. In D. N. Sudnow (ed.), Studies in Social Interaction, 294-338. New York: The Free Press.

Kendrick, Kobin H. (2015). The intersection of turn-taking and repair: The timing of other-initiations of repair in conversation. Frontiers in Psychology 6(250): 1-16. 
Lambrecht, Knud (1994). Information Structure and Sentence Form: Topic, Focus, and the Mental Representations of Discourse Referents. Cambridge, UK: Cambridge University Press.

Local, John (1996). Conversational phonetics: Some aspects of news receipts in everyday talk. In Elizabeth Couper-Kuhlen \& Margret Selting. (eds.), Prosody in Conversation, 177-230. Cambridge, UK: Cambridge University Press.

Peräkylä, Anssi \& Marja-Leena Sorjonen, eds. (2012). Emotion in Interaction. New York, Oxford University Press.

Persson, Rasmus (2015). Registering and Repair-Initiating Repeats in French Talk-in-Interaction. Discourse Studies 17(5): 583-608.

Pierrehumbert, Janet B. (1980). The Phonology and Phonetics of English Intonation. PhD thesis, MIT. Bloomington: Indiana University Linguistics Club.

Pierrehumbert, Janet \& Julia Hirschberg (1990). The meaning of intonational contours in the interpretation of discourse. In P. R. Cohen, J. Morgan \& M. E. Pollack (eds.), Intentions in Communication, 271-311. Cambridge, MA: MIT Press.

Quirk, Randolph, Sidney Greenbaum, Geoffrey Leech, \& Jan Svartvik (1972). A Grammar of Contemporary English. London: Longman.

Reber, Elisabeth (2012). Affectivity in Interaction. Sound objects in English. Amsterdam: Benjamins. Robinson, Jeffrey D. (2013). Epistemics, action formation, and other-initiation of repair: the case of partial questioning repeats. In Makoto Hayashi, Geoffrey Raymond, \& Jack Sidnell (eds.), Conversational Repair and Human Understanding, 411-465. Cambridge, UK: Cambridge University Press.

Schegloff, Emanuel A. (1997). Practices and Actions: Boundary Cases of Other-Initiated Repair. Discourse Processes 23(3): 499-546.

Schegloff, Emanuel A. (2007). Sequence Organization in Interaction: A Primer in Conversation Analysis. Cambridge, UK: Cambridge University Press. 
Schegloff, Emanuel A., Gail Jefferson \& Harvey Sacks (1977). The preference for self-correction in the organization of repair in conversation. Language 53: 361-382.

Selting, Margret (1996). Prosody as an activity-type distinctive cue in conversation: the case of so-called 'astonished' questions in repair. In Elizabeth Couper-Kuhlen \& Margret Selting (eds.), Prosody in Conversation, 231-270. Cambridge, UK: Cambridge University Press.

Walker, Gareth (2017). Visual representations of acoustic data: A survey and suggestions. Research on Language and Social Interaction 50(4): 363-387.

Walker, Traci C. \& Trevor Benjamin (2017). Phonetic and sequential differences of other-repetitions in repair initiation. Research on Language and Social Interaction 50(4): 330-347.

Wilkinson, Sue \& Celia Kitzinger (2006). Surprise as an interactional achievement: Reaction tokens in conversation. Social Psychology Quarterly 69(2): 150-182.

\footnotetext{
${ }^{1}$ These terminological distinctions are based on Cruttenden (1986: 52).

${ }^{2}$ The intonation unit (or group or phrase) consists of minimally one primary accent and is typically delimited at its edges by brief pauses or other breaks in the pitch and timing of unstressed syllables. ${ }^{3}$ More complex patterns such as fall-rise-fall or rise-fall-rise as well as bi-accentual patterns such as fall+rise and rise+fall are also recognized (see, e.g., Cruttenden 1986: 58ff).

${ }^{4}$ The distinction between a final pitch accent and the pitch on the last syllable of an intonation unit is especially clear when there are post-nuclear syllables. When the nuclear syllable is the last syllable in the unit, the 'boundary tone' is perceptually inseparable from the pitch accent.

${ }^{5}$ Grice and Bauman observe, for instance, that "for a large number of languages it is not a final rise but an accentual rise which marks polar questions" (2007: 39). See also Rossi this issue b.

${ }^{6}$ To date, there are only anecdotal observations concerning differences between British and American intonation, e.g., in polar questions (see Bolinger 1998; also Cruttenden 1986: 142f). To my knowledge, no empirical studies have been carried out examining intonational similarities and differences between the two varieties in the way sequentially specific actions are implemented in everyday talk.

${ }^{7}$ Lexical repetitions are to be distinguished from pro-form repetitions such as she did? or isn't it. The latter are widespread in English conversation but were excluded from this study for reasons of crosslinguistic comparability.
} 
${ }^{8}$ This and all following extracts have been transcribed according to the conventions of GAT II (see Couper-Kuhlen and Barth-Weingarten 2011).

${ }^{9}$ The production of the last name here can be seen as a form of specification (see next section). However, the repair operation made relevant by seeking completion, though it may encompass specification as in this case, is meaningfully distinct from it: (a) completion involves the provision of an element that must be complementary to the one being repeated (not any form of specification); (b) the complementary element may be something that was indeed said in the original turn, but that the repetition speaker did not catch (here the repair operation is unrelated to specification).

${ }^{10}$ In this and all further Praat pictures, the horizontal dotted lines represent the upper and lower bounds for pitch in the speaker's normal speaking voice (see also Walker 2017).

${ }^{11}$ Despite the fact that this contour rises to high, it is not the same as the 'high-rise question contour' described by Hirschberg \& Ward (1995), which begins high.

${ }^{12}$ Overlapping talk by Donna has been removed for the sake of clarity.

${ }^{13}$ Donna is indeed somewhat older than college-age Laura, being married with teenage sons.

${ }^{14}$ Note that in response to Babs' repetition, Amanda provides a simple confirmation (line 9), which Babs, after what is interpretably a display of resignation (line 10), reluctantly acknowledges (line 11). Thus, there is evidence in Babs' post-repetition non-verbal behavior that she has been disabused of her assumptions.

${ }^{15}$ Note that Chip seconds the challenge in lines 19 and 22, although he does not make use of repetition, and Bob subsequently persists in defending himself (lines 21, 23, 25).

${ }^{16}$ These syllables are themselves high, forming a plateau up to the focal syllable. 
Figure 1. Praat picture of line 14 in example (2). Pitch-accent type: level.

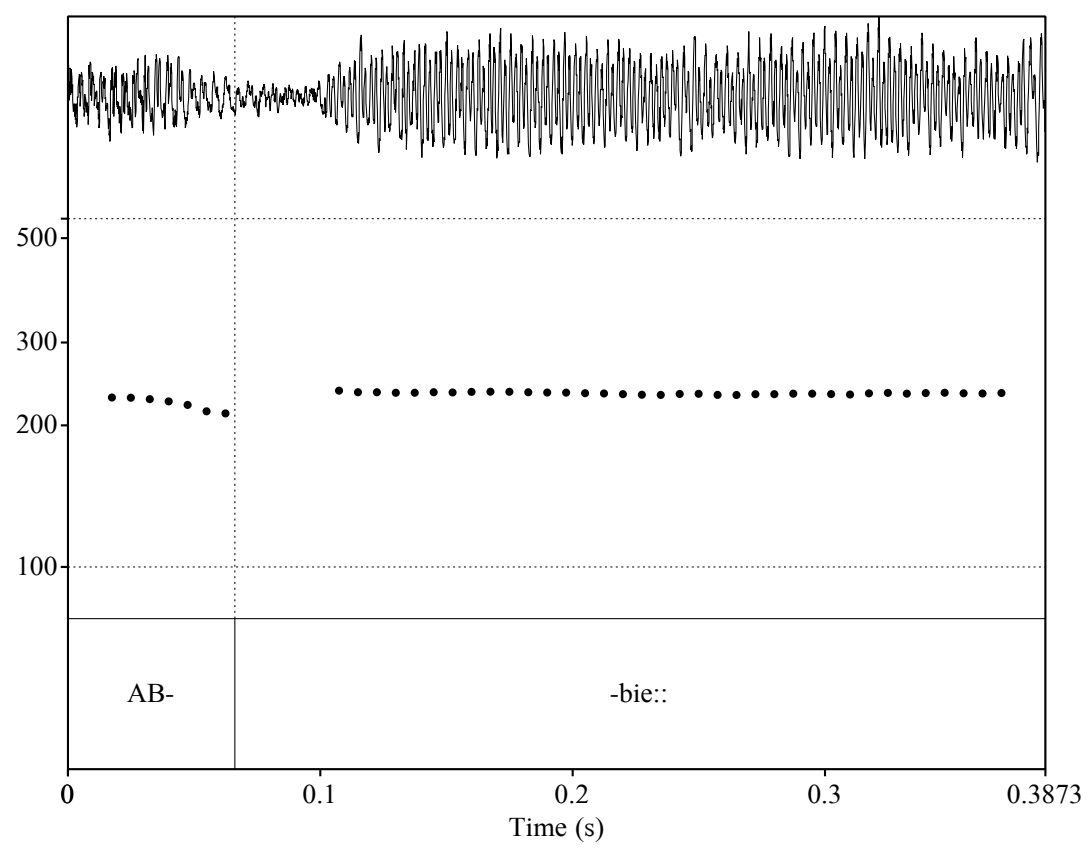


Figure 2. Pitch trace corresponding to line 16 in example (3). Pitch-accent type: fall from high.

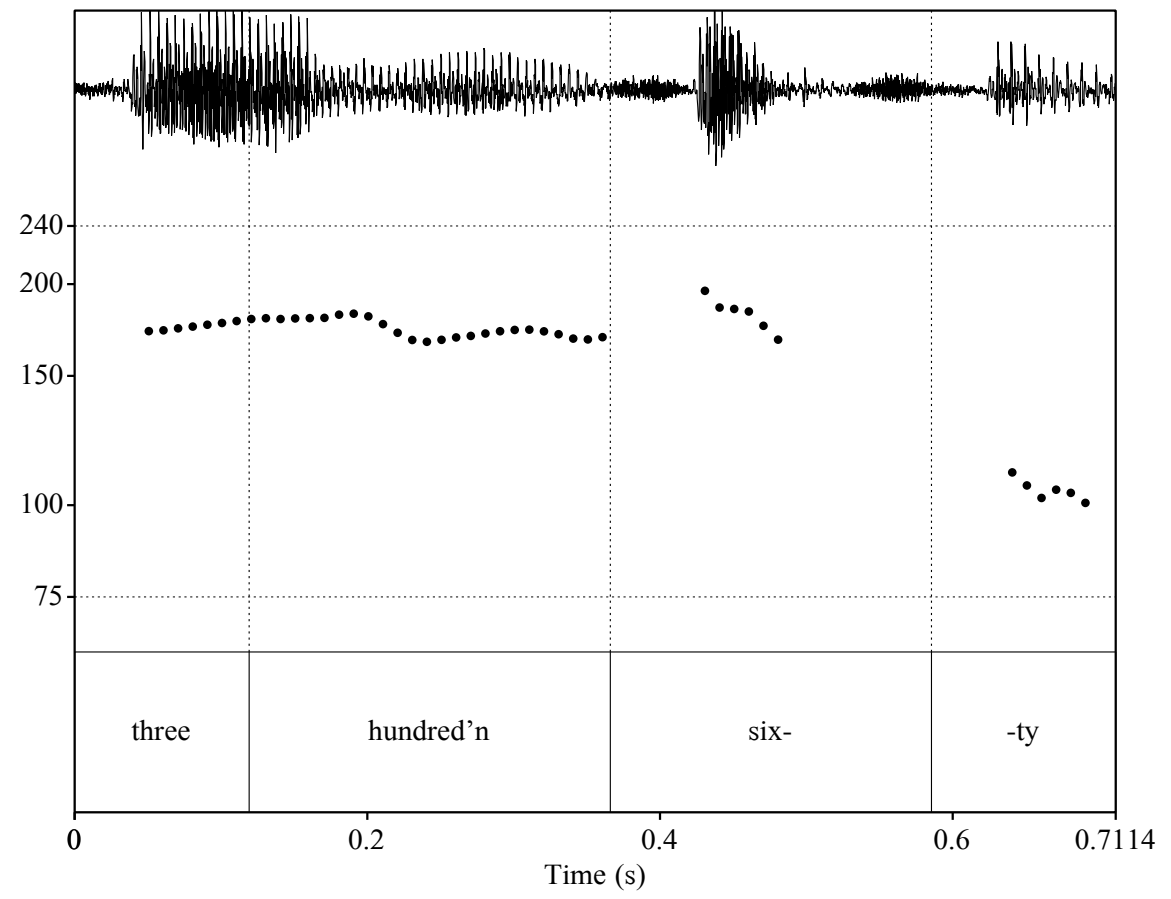


Figure 3. Pitch trace corresponding to line 7 in example (4). Pitch-accent type: rise from low.

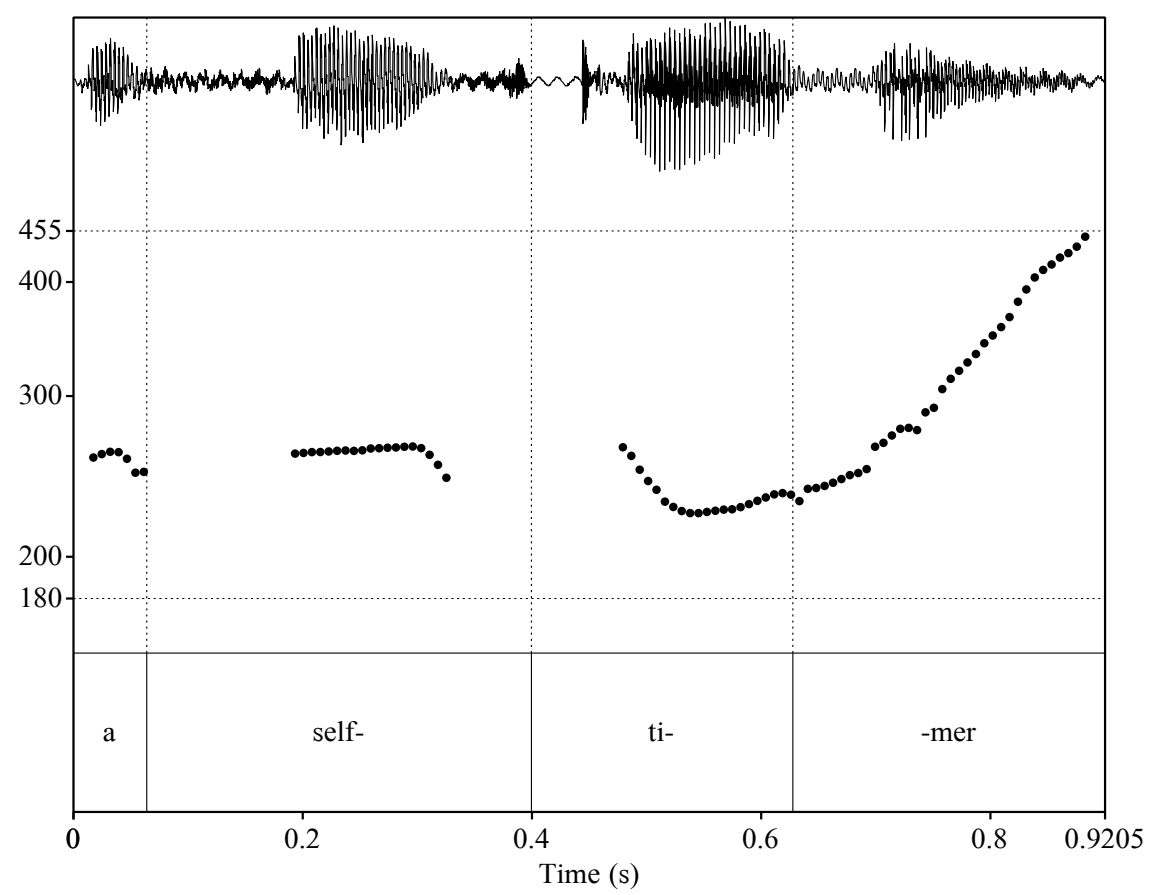


Figure 4. Pitch trace corresponding to line 9 in example (5). Pitch-accent type: fall from high.

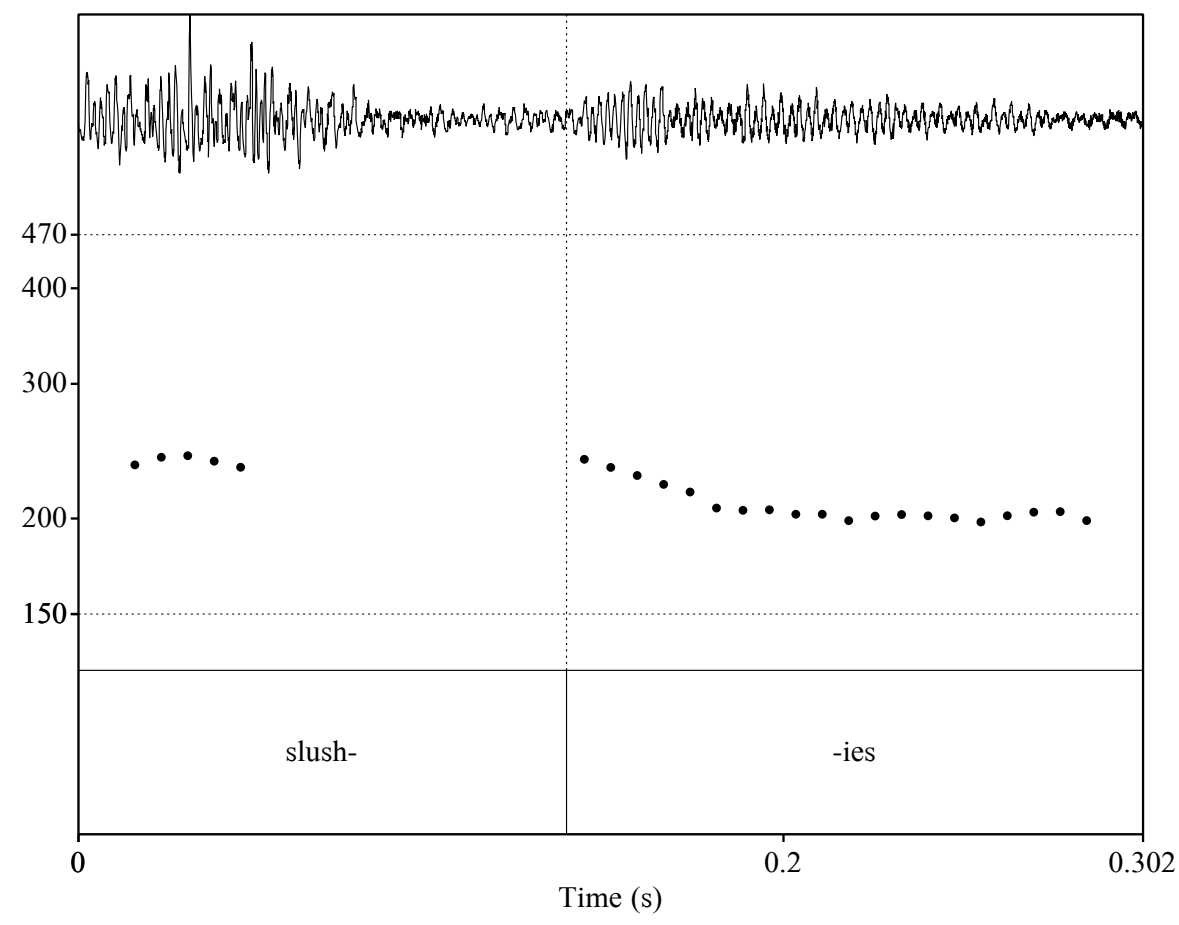


Figure 5. Pitch trace of line 16 in example (8). Pitch-accent type: high rise-fall.

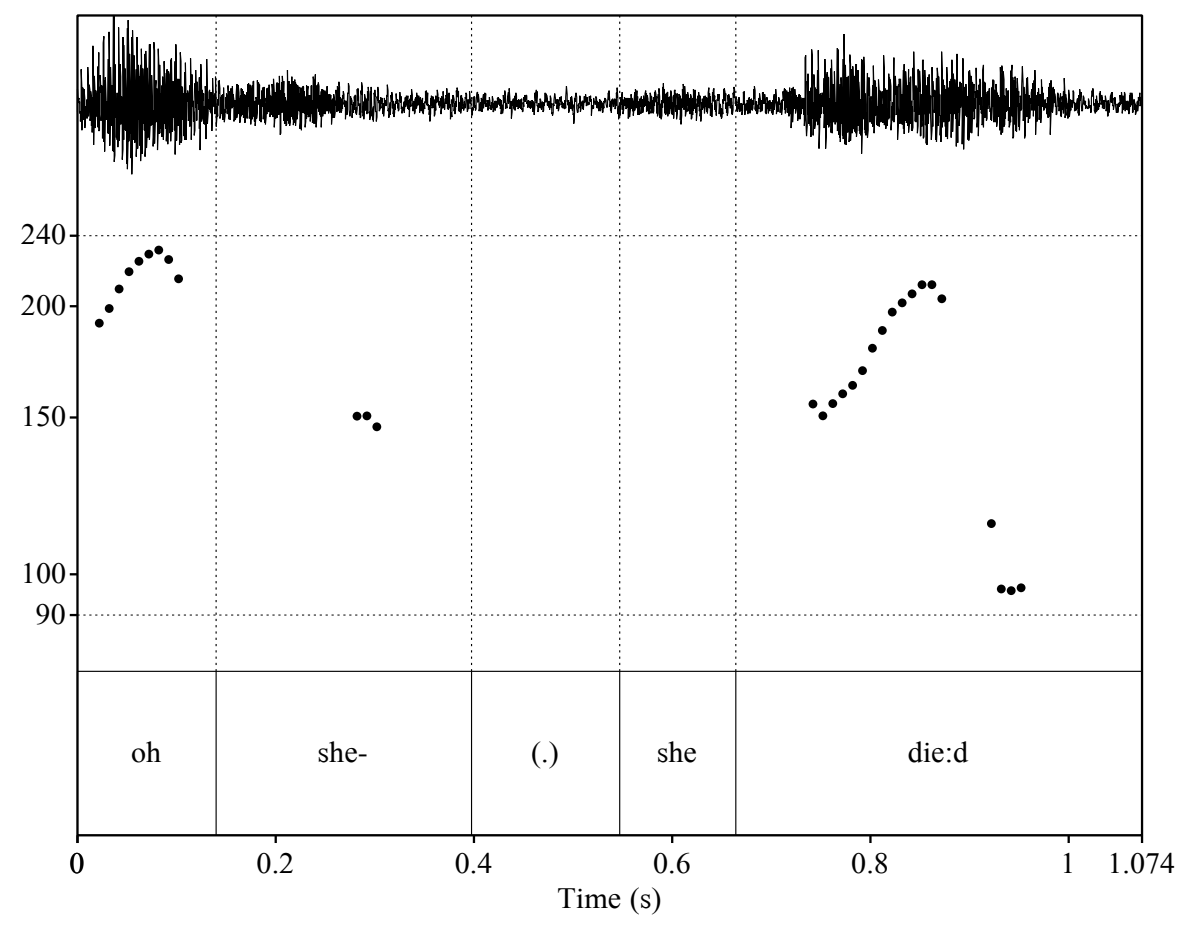


Figure 6. Pitch trace of line 14 in example (12). Pitch-accent type: fall from high.

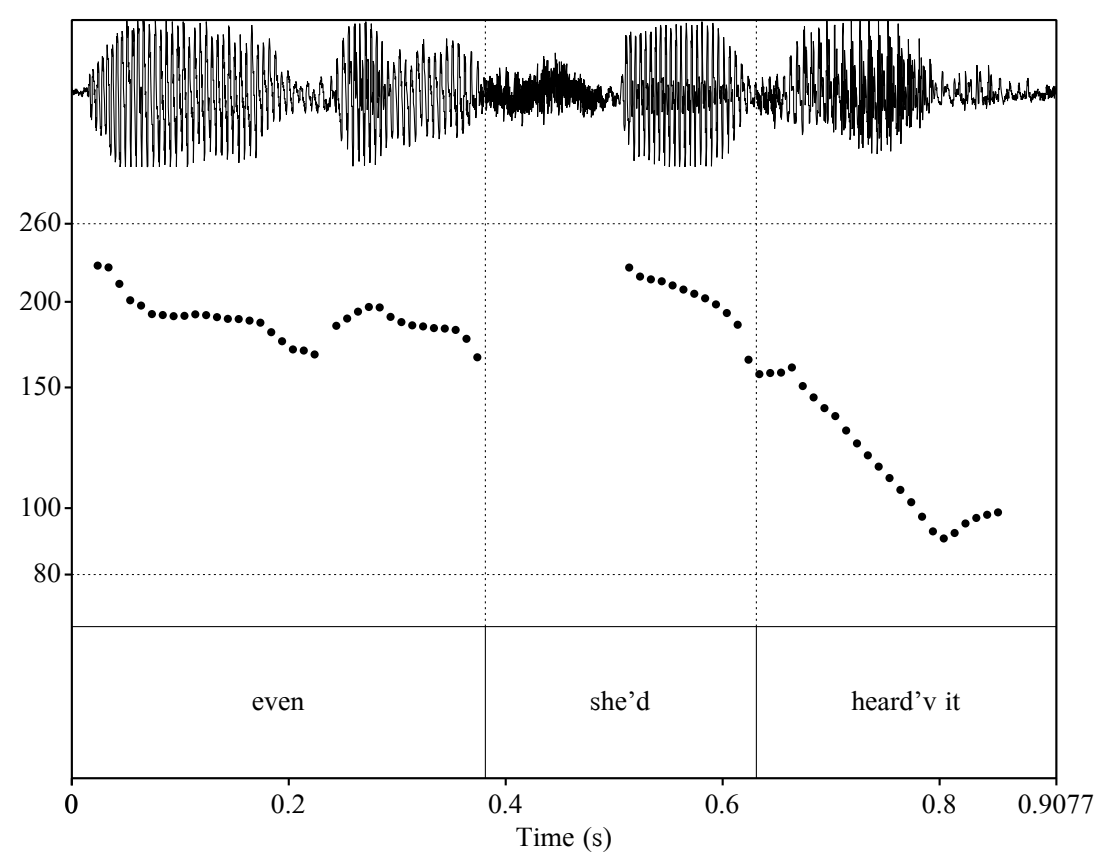


Figure 7. Pitch trace of line 11 in example (15). Pitch-accent type: Low fall.

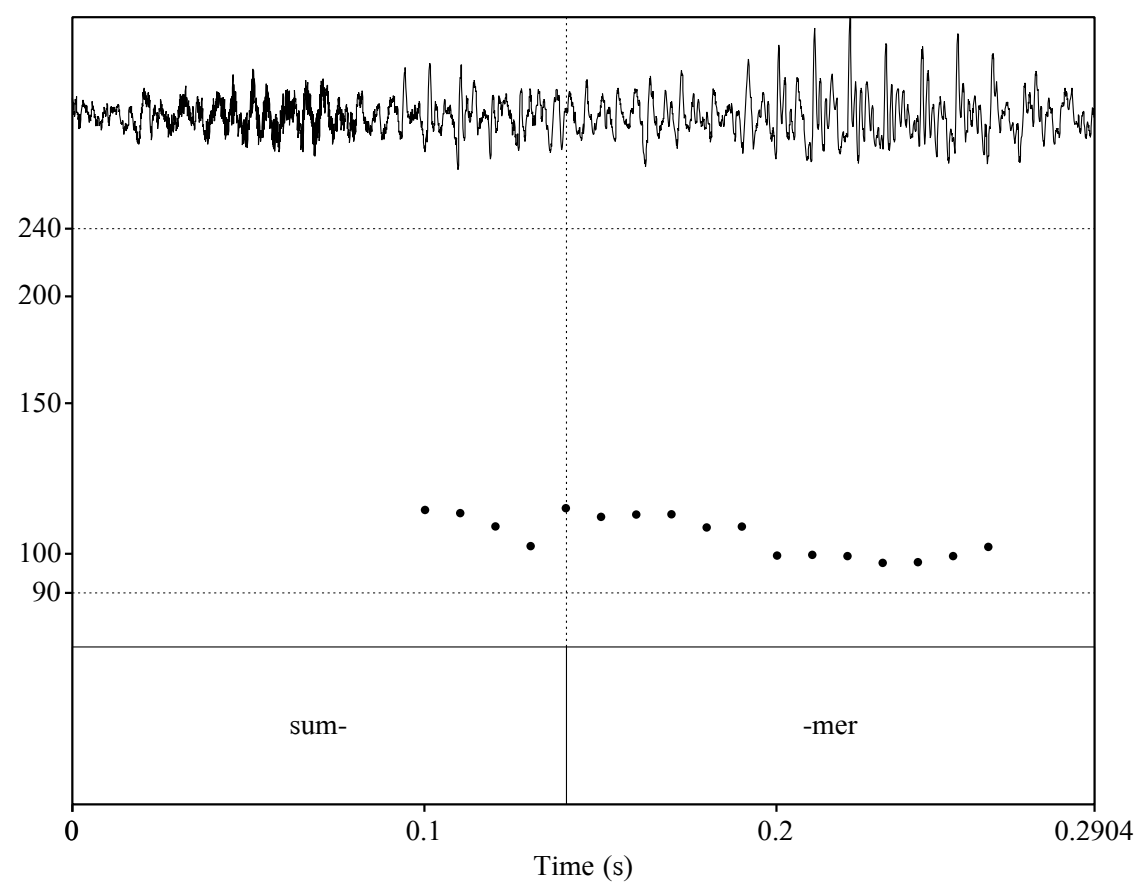


Table 1. Most frequent pitch contours for major other-repetition actions

\begin{tabular}{|c|l|l|}
\hline \multicolumn{1}{|c|}{ Other-repetition action } & \multicolumn{1}{|c|}{ British English } & \multicolumn{1}{c|}{ North American English } \\
\hline Repair initiation & & Level \\
\hline 1) Seeking completion & Level & $\begin{array}{l}\text { Rise from low } \\
\text { Fall from high ( } \pm \text { final rise })\end{array}$ \\
\hline $\begin{array}{c}\text { 2) Seeking clarification or } \\
\text { specification }\end{array}$ & Fall from high $( \pm$ final rise $)$ & Rise from low \\
\hline 3) Seeking confirmation & Fall from high $( \pm$ final rise $)$ & \\
\hline
\end{tabular}


Table 2. Most frequent pitch contours for major other-repetition actions

\begin{tabular}{|l|l|l|}
\hline \multicolumn{1}{|c|}{ Other-repetition action } & \multicolumn{1}{|c|}{ British English } & \multicolumn{1}{c|}{ North American English } \\
\hline Beyond repair initiation & $\begin{array}{l}\text { High rise-fall ( } \pm \text { final rise }) \\
\text { Fall from high }( \pm \text { final rise })\end{array}$ & $\begin{array}{l}\text { Fall from high ( } \pm \text { final rise }) \\
\text { Rise from low } \\
\text { High rise-fall ( } \pm \text { final rise })\end{array}$ \\
\hline 4) Surprise & $\begin{array}{l}\text { Fall from high }( \pm \text { final rise }) \\
\text { High rise-fall }( \pm \text { final rise })\end{array}$ & Rise from low $( \pm$ final rise $)$ \\
\hline 5) Disbelief or challenge & \multicolumn{2}{|l}{} \\
\hline
\end{tabular}


Table 3. Most frequent pitch contours for major other-repetition actions

\begin{tabular}{|l|l|l|}
\hline \multicolumn{1}{|c|}{ Other-repetition action } & \multicolumn{1}{|c|}{ British English } & North American English \\
\hline Other engagement & & \\
\hline 6) Registering & Low fall & Low fall \\
\hline
\end{tabular}


Table 4. Prosodic and non-prosodic cues to other-repetition actions in English

\begin{tabular}{|c|c|c|c|c|}
\hline \multirow{2}{*}{$\begin{array}{c}\text { Other-repetition } \\
\text { action }\end{array}$} & \multicolumn{2}{|c|}{ Pitch contours } & \multirow{2}{*}{$\begin{array}{c}\text { Other } \\
\text { prosodic } \\
\text { features }\end{array}$} & \multirow{2}{*}{$\begin{array}{c}\text { Non- } \\
\text { prosodic } \\
\text { resources }\end{array}$} \\
\hline & British English & $\begin{array}{c}\text { North American } \\
\text { English }\end{array}$ & & \\
\hline Repair initiation & & & & \\
\hline $\begin{array}{l}\text { 1)Seeking } \\
\text { completion }\end{array}$ & Level & Level & Lengthening & $\begin{array}{l}\text { Possible } \\
\text { incomplete } \\
\text { syntax }\end{array}$ \\
\hline $\begin{array}{l}\text { 2) Seeking } \\
\text { clarification or } \\
\text { specification }\end{array}$ & $\begin{array}{l}\text { Fall from high }( \pm \\
\text { final rise })\end{array}$ & $\begin{array}{l}\text { Rise from low } \\
\text { Fall from high }( \pm \text { final } \\
\text { rise })\end{array}$ & $\begin{array}{l}\text { Delay in } \\
\text { transition } \\
\text { timing }\end{array}$ & {$[\mathrm{K}-]$} \\
\hline $\begin{array}{l}\text { 3) Seeking } \\
\text { confirmation }\end{array}$ & $\begin{array}{l}\text { Fall from high }( \pm \\
\text { final rise) }\end{array}$ & Rise from low & $\begin{array}{l}\text { No delay in } \\
\text { transition } \\
\text { timing }\end{array}$ & $\begin{array}{l}\text { Partially } \\
{[\mathrm{K}+]}\end{array}$ \\
\hline $\begin{array}{l}\text { Beyond repair } \\
\text { initiation }\end{array}$ & & & & \\
\hline 4) Surprise & $\begin{array}{l}\text { High rise-fall ( } \pm \text { final } \\
\text { rise) } \\
\text { Fall from high ( } \pm \\
\text { final rise) }\end{array}$ & $\begin{array}{l}\text { Fall from high ( } \pm \text { final } \\
\text { rise) } \\
\text { Rise from low } \\
\text { High rise-fall ( } \pm \text { final } \\
\text { rise })\end{array}$ & $\begin{array}{l}\text { Wide pitch } \\
\text { span, } \\
\text { increased } \\
\text { loudness, } \\
\text { possible delay } \\
\text { in transition } \\
\text { timing }\end{array}$ & $\begin{array}{l}\text { [K-], } \\
\text { oh-prefacing, } \\
\text { facial } \\
\text { expression, } \\
\text { e.g., raised } \\
\text { eyebrows }\end{array}$ \\
\hline
\end{tabular}




\begin{tabular}{|l|l|l|l|l|}
\hline $\begin{array}{l}\text { 5) Disbelief or } \\
\text { challenge }\end{array}$ & $\begin{array}{l}\text { Fall from high } \pm \\
\text { final rise }) \\
\text { High rise-fall }( \pm \text { final } \\
\text { rise) }\end{array}$ & $\begin{array}{l}\text { High rise-fall }( \pm \text { final } \\
\text { rise) } \\
\text { Rise from low }\end{array}$ & $\begin{array}{l}\text { Wide pitch } \\
\text { span, } \\
\text { increased } \\
\text { loudness }\end{array}$ & $\begin{array}{l}\text { Partially } \\
{[\mathrm{K}+],} \\
\text { No oh- } \\
\text { prefacing }\end{array}$ \\
\hline $\begin{array}{l}\text { Other } \\
\text { engagement }\end{array}$ & Low fall & Low fall & $\begin{array}{l}\text { Narrow pitch } \\
\text { span, } \\
\text { low volume, } \\
\text { mirroring of } \\
\text { prosodic } \\
\text { contour in first } \\
\text { saying }\end{array}$ & \\
\hline
\end{tabular}

